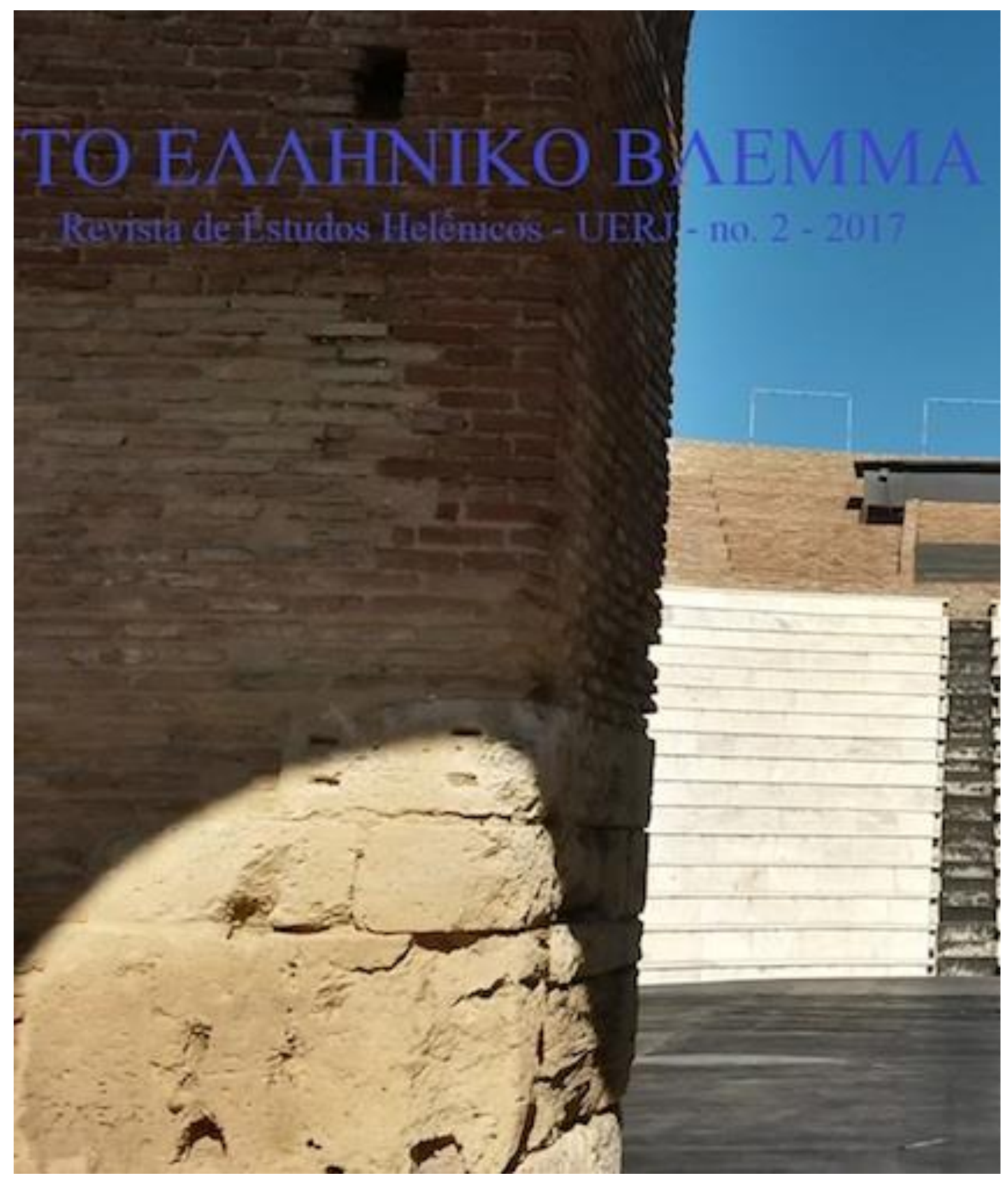




\title{
O Surgimento da Retórica e sua Evolução até Aristóteles
}

\author{
Elisa Costa Brandão de Carvalho - UERJ \\ lcbrandao@yahoo.com.br
}

\begin{abstract}
Resumo
Este artigo tem por finalidade traçar um panorama acerca do surgimento da retórica, do seu desenvolvimento, da sua importância no cotidiano e na educação do cidadão grego e da sua relevância na literatura da época. Abordaremos, também, a sua evolução a partir do século $\mathrm{V}$ a. C. com os sofistas até o advento de um tratado sobre retórica que, até hoje é o marco nos estudos da arte de persuadir, Arte Retórica de Aristóteles.
\end{abstract}

Palavras-chave: retórica, oratória, persuasão, filosofia, logos.

\section{The emergence of rhetoric and its evolution to Aristotle}

\begin{abstract}
The purpose of this article is to outline the emergence of rhetoric, its development, its importance in everyday life and the education of the Greek citizen, and their relevance in the literature of the time. We will also address its evolution from the century $\mathrm{V}$ a. $\mathrm{C}$. with the sophists until the advent of a treatise on rhetoric that, to this day is the mark in the studies of the art of persuading, Aristotle's Rhetoric Art.
\end{abstract}

Keywords: rhetoric, oratory, persuasion, philosophy, logos.

Uma das principais características da sociedade grega era a oralidade de sua língua. O grego precisava falar bem em seu dia a dia para convencer o seu público e, desta forma, exercer sua cidadania plenamente. A própria literatura grega tinha uma origem oral, o que a torna mais evidente se examinarmos os diferentes gêneros literários. A poesia dramática era feita para ser declamada ou cantada. A própria filosofia, talvez, tenha tido sua origem em máximas populares e cosmologias transmitidas oralmente, isto sem falar na oratória, que evidentemente encontrava seu ápice na expressão oral diante de um público. Por isso um dos principais interesses dos gregos era a retórica.

Mesmo em sua expressão escrita, toda esta literatura deriva muito de seu vigor, de seus aspectos orais. Na poesia lírica, por exemplo, isto é, particularmente nas diferentes preces e exortações que encontramos na obra de poetas como Safo e Calino. Quando lemos hoje tragédias e comédias áticas, é inevitável imaginar como seriam estas obras na encenação, já que o nosso entendimento se baseia na obra escrita. Na verdade, a retórica está sempre ligada à persuasão, a qual está presente nestes diferentes gêneros. Devido ao papel exercido pela oralidade e pela persuasão na sociedade grega, papel este que se reflete na própria literatura, é natural que a retórica assumisse grande relevo na educação dos gregos e, posteriormente, dos 
romanos. O aprendizado do bem falar para persuadir era bastante extenso e tinha grande utilidade.

Dentro deste contexto é importante analisar a palavra grega para discurso: lógos. Tal palavra tem uma vasta gama de significados, assumindo, às vezes, até uma conotação mística. Na verdade, lógos tem dentro do grego uma tríplice significação principal, significando palavra, vocábulo, daí aglomerado de palavras, discurso, e finalmente conteúdo do discurso, raciocínio. É este último significado que assume um valor filosófico, motivando a tradução, feita por Cícero, da palavra lógos como ratio. Há uma famosa passagem de Isócrates (Nícocles 5ss, reproduzido em Antidosis 253ss) que assinala lógos como conceito básico da civilização humana, já se distingue os homens dos animais.

Segundo a teoria tradicional, a retórica é dividida em cinco partes. A primeira é a héuresis ou inuentio e trata do conteúdo dos discursos. Nesta parte, se encontra a tradicional divisão aristotélica dos discursos em três gêneros: o judiciário ou forense, formado de discursos empregados em causas jurídicas perante tribunais; o deliberativo, formado de discursos sobre causas políticas enunciados perante assembleias; e o epidictico ou demonstrativo, formado de discursos sobre questões gerais enunciados perante um público não específico. $\mathrm{N}$ a verdade, o gênero epidíctico veio englobar todos os discursos que não encontravam lugar nem no gênero deliberativo nem no gênero judiciário. A segunda parte da retórica é a táxis ou dispositio, a qual trata da organização das diferentes partes de um discurso. As divisões básicas do discurso são geralmente a introdução ou proêmio (prooímion, exordium), a narração (diégesis, narratio), a prova (pistis, probatio) e o epílogo ou conclusão (epílogos, peroratio). A terceira parte da retórica é a léxis ou elocutio, a qual trata do estilo do discurso. A quarta parte é a memória (mnéme, memória), a qual trata de expedientes mnemônicos para a memorização do discurso. A quinta parte é a hypókrisis ou actio, que trata do desempenho do orador durante a enunciação do discurso, entrando aí, entre outras coisas, o estudo da modulação da voz e da gesticulação.

Na Antiguidade houve uma vasta tradição de escritos sobre a teorização da retórica. Apenas alguns destes escritos chegaram até nós, mas mesmo assim podemos ter a visão bastante abrangente de um fio contínuo da tradição retórica antiga que chega até os romanos, encontrando nestes a sua expressão mais completa, através das Institutiones Oratoriae de Quintiliano.

Através destes escritos retóricos podemos perceber que, apesar de seu grande relevo na educação e na civilização da Antiguidade Clássica, houve uma contestação à importância da retórica por parte de alguns filósofos. Para bem entendermos esta contestação faz-se necessário remontar até o movimento sofístico, surgido no século $\mathrm{V}$ a. C.. Os sofistas foram os primeiros a ensinar a arte de falar bem para conseguir a persuasão do ouvinte. Foram, portanto, os primeiros mestres da retórica, e entre eles destacaram-se Protágoras e Górgias. Na verdade, o ensinamento sofístico era relativista: nele todos os argumentos eram válidos para defender uma causa, fosse ela boa ou má. Contra este relativismo surge Sócrates que, através da dialética, busca definições precisas e um padrão para uma verdade absoluta. No ensinamento de Sócrates estariam os germes da doutrina platônica sobre a retórica, contida, sobretudo, nos diálogos Górgias e Fedro. Platão desvaloriza a retórica, afirmando que a dialética lhe é essencialmente superior. A retórica, para Platão, não teria o estatuto de uma "arte" (téchne) e, portanto, não é passivel de teorização. As opiniões de Platão contra a retórica são, de resto, bem mais acentuadas no Górgias que no Fedro. Neste último diálogo, Platão reconhece até que a retórica existe e tem alguma utilidade. $\mathrm{Na}$ verdade, as opiniões platônicas contra a retórica não atingem apenas os pensamentos de seu mestre Sócrates, mas também o desprezo essencial que Platão nutria pela forma de vida política em Atenas, incluída aí a liberdade de palavra.

A reação contra as controvertidas opiniões socráticas e platônicas acerca da retórica deu-se de imediato. Isócrates deu a Platão uma resposta de caráter essencialmente prático. Para Isócrates, a retórica tinha grande valor para o cidadãona 
medida em que era importante o falar bem no cotidiano da vida grega. Já Aristóteles, discípulo de Platão, deu ao mestre uma resposta teórica e filosófica. Embora em um diálogo juvenil, intitulado Gryllus, Aristóteles tenha assumido por inteiro as opiniões platônicas acerca do pouco valor da retórica, seu pensamento evoluiu muito até a Arte Retórica. Esta começa logo com a seguinte frase: "A retórica é correlativa (antístofros) cona dialética". Nenhuma das duas é superior à outra, mas ambas tratam dos mesmos assuntos de maneiras diferentes. Ao mesmo tempo, para Aristóteles, a retórica é uma "arte" (téchne) e, portanto, passível de teorização filosófica. O estagirita dá, portanto, um tratamento à retórica baseado bastante na lógica e na ética. , tratamento este imparcial e sem apologias da retórica.

Esta disputa entre a retórica e a filosofia é reflexo também do conflito existente entre dois modelos educacionais diferentes. Após Aristóteles, a polêmica acalmou-se bastante, e mesmo escolas filosóficas incluíram em seus currículos o estudo da retórica. Toda essa controvérsia refletiu-se também na educação romana, na qual a retórica era muito relevante. Ocasionalmente, a disputa entre filósofos e mestres de retórica ressurgiu ao longo da Antiguidade, mas sem a intensidade da época de Platão e Isócrates.

Nesta rivalidade é natural que o homem moderno procure assumir uma posição a favor da filosofia. A princípio esta parece ser a busca da verdade, enquanto a retórica não passaria do ensino de expedientes para a persuasão e, consequentemente, para a enganação. No entanto, a retórica tem suas virtudes, e, dentre estas, a principal é fornecer ao ser humano meios mais eficientes para a sua própria defesa e para a defesa de suas opiniões. Num sistema político-social onde a palavra é livre, a importância da retórica é evidente. A retórica apresenta também, sem dúvida, alguns defeitos, e dentre estes o maior é o fato de o orador muito hábil julgar-se onipotente em seu poder de persuasão, podendo defender com sucesso causas boas ou ruins.

Segundo uma tradição antiga, a arte da retórica teria sido inventada no século V a. C. em Siracusa, na Sicilia, por Córax e Tísias. Dali, teria passado a Atenas através do sofista Górgias de Leontinos, que veio numa embaixada à Ática em 427 a. C..

$\mathrm{Na}$ verdade, algumas circunstâncias fizeram com que os séculos V e IV a. C. se tornassem a idade de ouro da retórica e da oratória. Em primeiro lugar, através da evolução judiciária, os tribunais passaram a ter júris muito grandes, com um mínimo de duzentos e um integrantes. Perante tantos jurados era necessária grande habilidade de persuasão. Ao mesmo tempo, a democracia evoluía politicamente e os cidadãos foram ganhando cada vez mais espaço para expor suas opiniões perante a assembleia.

É de se notar ainda que a consciência retórica na Grécia foi despertada nesta época por quatro fatores. O primeiro é o desenvolvimento do racionalismo nas provas e argumentos. Neste desenvolvimento inclui-se o uso do argumento por probabilidade. O desenvolvimento de argumentações mais sutis e trabalhadas atesta não apenas um progresso na retórica, mas também está fundada no princípio de que a justiça, mesmo existindo em forma absoluta, não é sempre óbvia, e deve ser descoberta através da racionalidade humana.

Outro fator é o interesse que surge em dividir os discursos em partes, cada uma com uma função individual.

Um terceiro fator é o interesse manifestado na busca de novos estilos de prosa. Nesta busca destaca-se o gosto pela antitese. Se examinarmos a literatura grega, veremos que esta figura estava profundamente enraizada no espírito helênico.

Finalmente, o quarto fator consiste no interesse crescente pelas linguagem propriamente dita. Tal interesse mostra-se na nascente ciência da filologia. Vários sofistas dedicaram-se a estudos sobre a língua, e o diálogo de Crátilo de Platão atesta o interesse pelas etimologias.

No século $\mathrm{V}$ a. C., teve inicio a teorização retórica, mas na literatura grega técnicas de persuasão oratória são bem evidentes já nos poemas homéricos. Com 
efeito, nas epopeias homéricas temos vários tipos de discurso. No canto IX da Míada, Fênix, o preceptor de Aquiles, diz que o tinha educado para ser um "praticante de atos e falador de discursos" (VV 442-443). Não só a atividade guerreira é valorizada nos poemas homéricos, mas também a eloquência faz parte da areté (virtude) heroica. $\mathrm{Na}$ líada, de resto, cada herói tem seu estilo de falar.

A argumentação apresentada nos discursos homéricos é bastante fraca do ponto de vista lógico. Encontramos ali exemplos de persuasão através do uso de evidências diretas, referências ao caráter do orador, exemplos ou apelos à emoção do ouvinte, sem o uso do argumento por probabilidade. Aliás, poucos discursos registrados em Homero poderiam ser classificados dentro do que hoje entendemos como oratória real, sendo a maioria antes da conversação.

Prosseguindo na trilha da literatura grega, vemos que a obra Os trabalhos e os Dias de Hesíodo é por inteiro uma tentativa de persuadir seu irmão Perses. O mesmo caráter persuasivo vemos em muitas obras da lírica arcaica. No Hino Homérico a Hermes encontramos pela primeira vez algo que se aproxima de uma disputa forense onde é usado o argumento por probabilidade. Para defender-se da acusação de ter roubado os rebanhos de Apolo, Hermes apresenta o argumento de que ele é uma criança e, portanto, não pode ser um ladrão. Nas Eumênides de Ésquilo encontra-se mais uma cena de disputa forense, em que o acusado é Orestes. Ali Apolo atua como testemunha e virtual advogado de defesa e Atena como juiza. Os discursos proferidos por Orestes, por Apolo e pelas Erínias mostram já uma argumentação bastante desenvolvida para uma questão bastante complexa. Em Heródoto também já se nota um certo interesse por coisas que mais tarde seriam associadas à retórica. Há vários discursos inseridos em sua obra, mas, como em Homero, a melhor parte do discurso direto inserido na obra está, do ponto de vista argumentativo, nos diálogos e não na oratória. Podem-se ainda encontrar em Heródoto as quatro características da consciência retórica já enumeradas, assim como o argumento por probabilidade.

O estudo das características retóricas já presentes em Ésquilo e em Heródoto demonstra bem que a retórica não foi introduzida como algo novo em Atenas por Górgias em 427 a. C.. no entanto, é necessário ter consciência da tremenda impressão que as técnicas retóricas deste orador causaram no público ateniense. Já em Tucídides a técnica oratória difere da técnica de Heródoto sobretudo em grau de intensidade. A retórica envolve o estilo de Tucídides em grau ainda maior que o de Heródoto. Ainda em termos de estilo temos a antítese, figura principal empregada por Tucídides em orações, frases ou discursos inteiros.

A instrução retórica no século $\mathrm{V}$ a.C. era dada de duas maneiras diferentes: em primeiro lugar, eram fornecidos lugares comuns, ou seja, discursos inteiros ou mesmo partes de discursos ou mesmo apenas frases para a análise dos alunos, formando uma instrução através da exemplificação; em segundo lugar, havia a instrução através de manuais de retórica, os quais eram compostos de exposições de preceitos através de uma teorização sobre o assunto. Pelas referencias contidas em Platão, Aristóteles e Isócrates, estes manuais eram em grande número. Nenhum destes manuais mais primitivos chegou até nós, mas sabe-se que Aristóteles, antes de escrever seu próprio tratado retórico, compilou-os em uma obra intitulada Synagogé Technôn.

Da segunda metade do século IV a. C., possuímos dois tratados completos sobre retórica. Um deles, a chamada Retórica de Alexandre, enquadra-se como um produto típico da tradição retórica primitiva. O outro é a Arte Retórica de Aristóteles, a qual se baseia profundamente nos estudos feitos pelo estagirita acerca da ética, da política e da lógica. Para bem compreendermos a Retórica de Aristóteles é necessário ter duas coisas em mente. Em primeiro lugar, a obra não surgiu repentinamente, mas através de um desenvolvimento gradual, como, aliás, toda a filosofia aristotélica. Em segundo lugar, é necessário levar em consideração a influência exercida por Platão, mestre de Aristóteles. Com efeito, varias passagens da Retórica parecem desenvolver sugestões de Platão ou são respostas a objeções feitas pelo mestre. 
Mesmo em uma primeira leitura da Retórica de Aristóteles notam-se inconsistências na ordenação dos assuntos e repetições. Para explicá-las os eruditos modernos têm elaborado teorias acerca da ordem em que foram escritos os diferentes livros da Retórica. Nesta questão Kennedy aceita as teorias de Friedrich Solmsen, que é substancialmente um desenvolvimento das teorias de A. Kantelhardt e de Werner Jaeger.

Segundo esta teoria, há uma certa evolução nas teorias de Aristóteles sobre a retórica. Em um diálogo juvenil, intitulado Gryllus, Aristóteles defende as teorias de Platão acerca da retórica, desvalorizando-a em sua própria essência. Em seguida o estagirita escreveu um tratado sobre retórica que se encontra contido no que hoje conhecemos como os livros I e II da Retórica. Neste tratado de Aristóteles desenvolve o estudo do entimema.

A Retórica é o resultado de três etapas posteriores. Em uma primeira etapa Aristóteles aplica ao estudo da retórica sua teoria acerca da lógica, incluindo aí a caracterização do entimema. Em segundo lugar, seguindo a sugestão de Platão exposta no Fedro, ele adiciona à argumentação lógica a psicológica, a fim de obter uma persuasão mais eficaz. Finalmente, em terceiro lugar, aproximando-se mais da teoria retórica antiga, ele estuda o estilo das partes do discurso.

Aristóteles distinguiu ainda três tipos de oratória: a judiciária, a deliberativa e a epidictica. Esta distinção foi feita em primeiro lugar pelo Estagirita, já que os tratadistas a ele anteriores ocupavam-se apenas com a oratória judiciária. Tal divisão tornou-se posteriormente tradicional, apesar de ser ligeiramente questionada por autores posteriores como Cícero e Quintiliano. Os eruditos modernos questionam, sobretudo os critérios usados pelos filósofo para esta classificação, critérios estes que vão desde o tipo de ouvinte até o conteúdo. Mesmo discursos daquela época não se deixam classificar facilmente em um ou outro dos três tipos.

Se contemplarmos em seu conjunto toda tradição retórica em seus primeiros cento e cinquenta anos, constatamos que a Arte Retórica de Aristóteles se destaca nitidamente de todos os outros tratados. Isto acontece não só por ser o mais rico nem por ter exercido a influência mais duradoura, mas, sobretudo porque Aristóteles é imparcial em seu tratamento. Ele não procura glorificar a retórica, mas sim mostrála como ela é, reconhecendo sua utilidade, mas advertindo contra seus perigos. Ninguém aprenderia a proferir discursos só por ler a Retórica, mas um orador bem treinado certamente tiraria muito proveito do livro.

\section{Referências Bibliográficas}

ARISTOTELES. Retorica. Tradução: Antonio Tovar. Madrid: Centro de Estudios Constitucionales, 1990.

DUMONT, Jean-Paul. A filosofia antiga. Lisboa: Ed.70, 1981.

KENNEDY, George. The Art of Persuasion in Greece. Princeton: Princeton University Press, 1963.

MORA, José F. Dicionário de filosofia. Lisboa: Dom Quixote, 1978.

VERNANT, Jean-Pierre. As origens do pensamento grego. São Paulo: Difel, 1984. 